\title{
Strain gauges made of laser patterned hot stamping foil
}

\author{
J. Hielscher ${ }^{1}$, A. Lyashenko ${ }^{2}$, D. Foik ${ }^{1}$, R. Werthschützky ${ }^{1}$ \\ ${ }^{1}$ Institute of Electromechanical Design, Technische Universität Darmstadt, \\ Merckstrasse 25, 64283 Darmstadt \\ j.hielscher@emk.tu-darmstadt.de \\ ${ }^{2}$ Institute of Printing Science and Technology, Technische Universität Darmstadt, \\ Magdalenenstrasse 2, 64289 Darmstadt, Germany
}

\begin{abstract}
Some applications require strain gauges with individual shape and resistance. We provide a fast and flexible method to create individually shaped low-cost strain gauges by laser patterning of hot stamping foil. The raw material is inexpensive, widely available and comes with a homogenous metallization. By a selective laser patterning process it is possible to create the sensitive metal structures in any individual layout and separate the foil into single pieces in a single operation. We used a conventional hot stamping foil with a gold coating and a fiber laser for the patterning. To investigate the performance, a generic meander layout was designed with a base resistance of $1 \mathrm{k}$ Ohm. 32 gauges were fabricated with a standard deviation in resistance of 48 Ohms. Four point bending tests reveal a gauge factor of $\mathrm{k}=2.61$.
\end{abstract}

Key words: Strain gauge, hot stamping, selective laser patterning, low-cost sensor

\section{Introduction}

Hot stamping foil is a product conventionally used for refining and beautifying surfaces, for instance packages and printings, or for security issues like passports and banknotes. In the hot stamping process, also known as foil stamping, a thin foil consisting of ink or metal is transferred on a surface using pressure and temperature. During the transfer process, the foil is cut in its designated shape by the stamping die and firmly bonded onto the surface. The most common materials for metalbased hot stamping foil are aluminum, silver and gold. Metal-based foils provide not only a beautiful and valuable visual effect, but also electrical conductivity. Since the raw material is cheap and widely available, the suitability for electrical devices, e.g. printed circuit boards is currently subject of research $[1,2]$. Furthermore, the vacuum deposited metal layer is thin and homogenous, yielding a promising source material for sensor applications, esp. strain gauges.

\section{State of the art}

Strain gauges are used to measure strain on surfaces. They are applied on the spring element in force and pressure transducers or onto surface of mechanical components provide information about the structural load and health. Foil gauges consist of a meander-shaped nickel-copper-alloy pattern mounted on a thin insulating carrier and are widely available in many shapes and for various purposes. Hysteresis and creep can be reduced by depositing the metal coating directly to the surface [3]. Laser ablation can be used to pattern the resistive layer even on curved surfaces [4]. Some applications require strain gauges with individual shape and resistance. Metal foil gauges with individual layout are available, however mostly associated with high costs and long manufacturing periods. Printing strain gauges with conductive ink is a fast and inexpensive approach for individually shaped sensing elements [5]. Due to piezoresistive effects, ink-based strain gauges can also achieve higher gauge factors. However, in many cases they show higher hysteresis and nonlinearity. Aiming to combine the precision and long-term stability of metal strain gauges and the possibility to create cheap, individually shaped gauges in a short time, we are working on strain gauges made of metal-based hot stamping foil.

\section{Structure of the stamping foil}

A generic hot stamping foil has a sequentially laminated multilayer structure. Figure 1 shows the structure of the investigated hot stamping foil HS-19-3 (HS Neuffer GmbH, Germany). A polyester base foil (approx. $20 \mu \mathrm{m}$ ) provides the 
carrier for the other layers. The release layer (approx. $1 \mu \mathrm{m}$ ) between the carrier and the protective coating provides for the possibility to peel off the carrier after the application. The metal coating (Au, $30-40 \mathrm{~nm}$ ) is covered with an adhesive film (approx. $15 \mathrm{~nm}$ ) on the bottom side and with a protective coating (approx. $1 \mu \mathrm{m}$ ) on top.

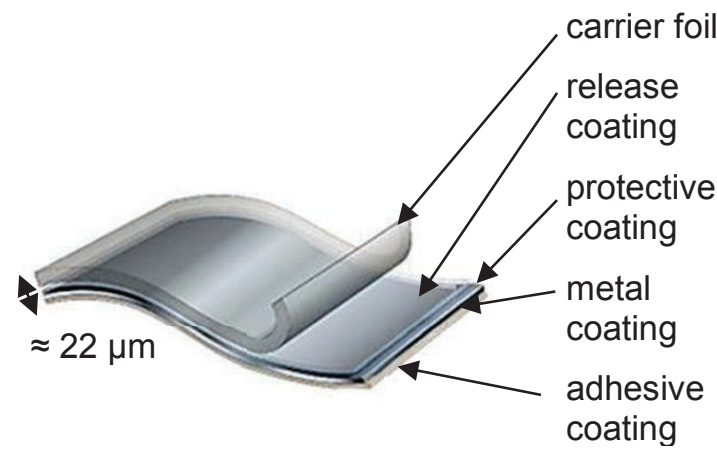

Fig. 1 Structure of the hot stamping foil HS-19-3 (HS Neuffer GmbH, Germany) [2].

\section{Strain gauge preparation}

Conventionally, during the hot stamping process the metal coating is transferred to the surface by a hot die, which also provides for the designated shape. This procedure is also suitable to create sensing structures, esp. strain gauges [2]. Another approach is to pattern the metal layer in a first step and subsequently transfer it to the surface. This can be achieved by a selective laser process: the metal-coating is removed by laser ablation in certain areas, whereas the carrier foil remains unaffected. Regarding the aim of low-cost individual strain gauges, laser patterning has some benefits: No expensive stamping die is needed and with a selective laser process, the gauges can be separated into single pieces in the same operation. Additionally, laser patterning achieves a higher spatial resolution. Lyashenko et. al. successfully prepared traces with a width of $150 \mu \mathrm{m}$ [2]. This yields to smaller gauges and higher precision of the intended base resistance.

A typical linear strain gauge layout was created with two solder terminals, an even number of meanders and thickened bridges to reduce the influence of transverse deformation. In preliminary investigations on the hot stamping foil HS19-3 we found a sheet resistance of approximately $R_{\square}=5 \Omega$. Thus, eight meanders with $5 \mathrm{~mm}$ length and $200 \mu \mathrm{m}$ width result in the intended base resistance of $R_{0}=1 \mathrm{k} \Omega$.

To generate the strain sensor structures, the stamping foil is patterned by a laser process in two steps. First, by selective laser patterning all layers except the polyester carrier are ablated. This is achieved using a marking laser (F-9020, KBA Metronic $\mathrm{GmbH}$, Germany) with reduced power $(2.4 \mathrm{~W})$. Subsequently, the strain gauges are separated using the same laser with increased power (20 W).

We produced 32 strain gauges using the described method as seen in figure 2. In table 1 the results of this process are listed.

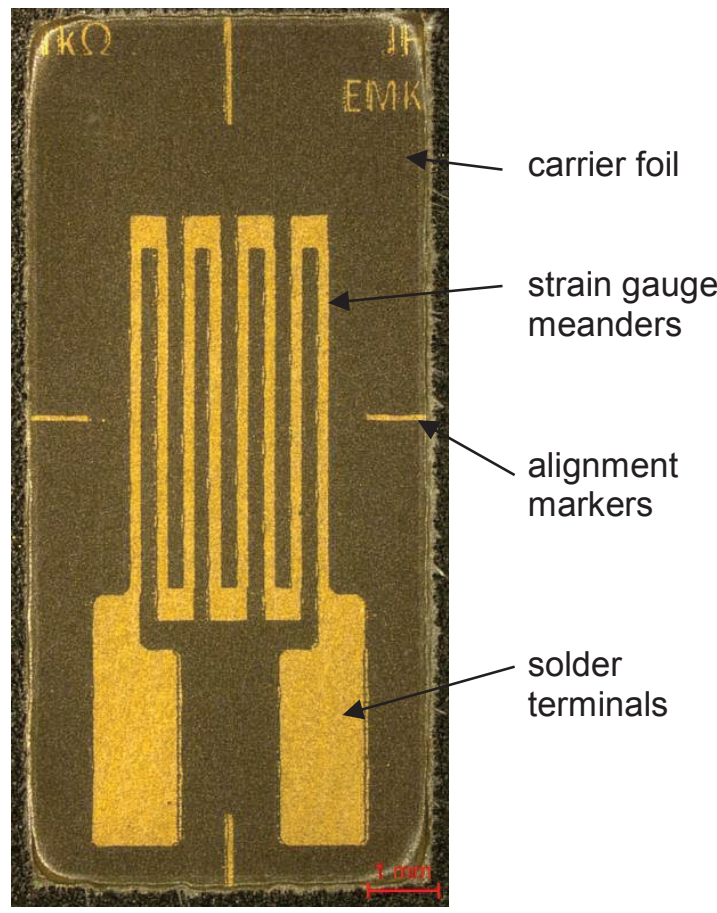

Fig. 2 Strain Gauge made of laser-patterned hot stamping foil with gold metallization. $R_{0}=1 \mathrm{k} \mathrm{Ohm}$.

Tab. 1: Resistances of the laser processed strain gauges

\begin{tabular}{|l|c|}
\hline broken & $1 / 32$ \\
\hline target base resistance & $1000 \Omega$ \\
\hline $\mathrm{R}_{0} \min$ & $981 \Omega$ \\
\hline $\mathrm{R}_{0} \max$ & $1107 \Omega$ \\
\hline standard deviation & $48 \Omega$ \\
\hline
\end{tabular}

\section{Strain gauge application}

Steel plates were prepared to examine the application of the gauges on a solid surface (Steel X10CrNi18-8, Hasberg GmbH, Germany, $\mathrm{L} \times \mathrm{W} \times \mathrm{H}: 90 \times 15 \times 1 \mathrm{~mm}^{3}$ ). To provide an electrical insulation a $100 \mathrm{~nm} \mathrm{SiO}{ }_{2}$ coating was sputtered on the plates.

The hot stamping foil already provides an adhesive coating, which is used to glue the 
strain gauge on the steel plate. We found, that at high temperatures $\left(>150^{\circ} \mathrm{C}\right)$, the carrier gets firmly bonded to the gold coating and cannot be removed without destruction of the sensing pattern. Best results for the application were achieved using pressure with a parallel screw clamp and a temperature of $70^{\circ} \mathrm{C}$ for four hours. With this setup, the polyester carrier can be peeled off and the sensing pattern remains intact and firmly bonded on the $\mathrm{SiO}_{2}$ surface (Fig.3). Subsequently, the gauges are connected by a conductive adhesive (Elecolit 414, Panacol GmbH, Germany). Glued solder pads and polyimide tape were added for cable relief.

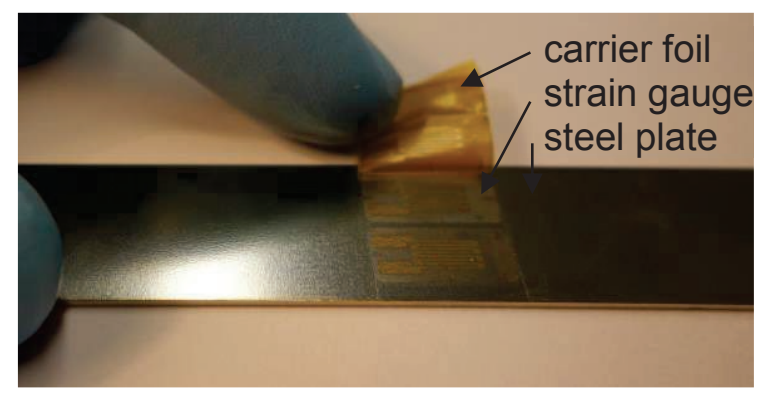

Fig. 3: Application of laser-patterned strain gauges on a steel plate. The carrier foil can be peeled off.

\section{Bending tests}

Four-point bending tests were carried out to investigate the performance to measure strain (Fig. 4). With this setup, a constant longitudinal strain can be adjusted in an area of $40 \mathrm{~mm}$ length on the surface of the steel plate. A laserpatterned strain gauge and a conventional

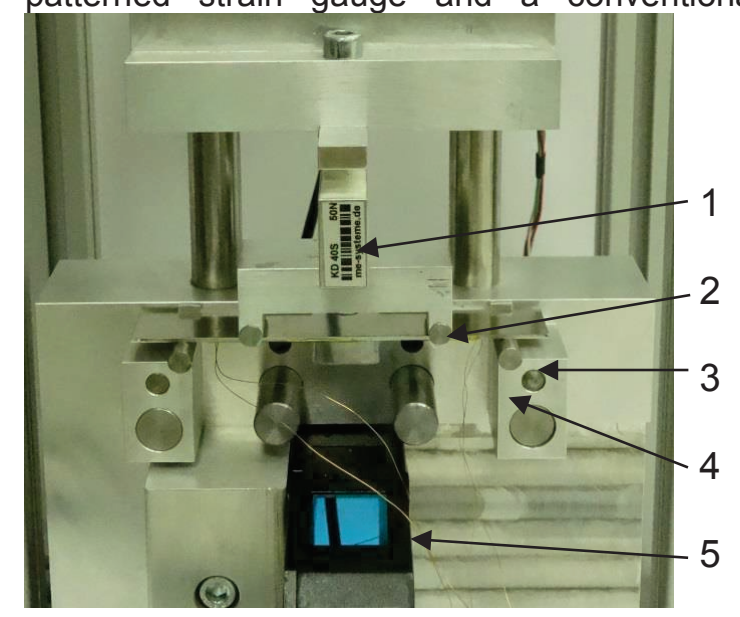

Fig. 4: Bending test setup. 1) Force sensor, 2) upper bending tool, 3) steel plate, 4) lower bending tool, 5) displacement sensor

strain gauge for reference (1-L Y11-3/120, Hottinger Baldwin Messtechnik $\mathrm{GmbH}$,
Germany) are applied in this area on the same steel beam. Both gauges are separately arranged in a Wheatstone quarter-bridge configuration. A two-channel bridge amplifier (Kistler SCP 5271) is used to provide the supply voltage $\left(\mathrm{V}_{0}=1 \mathrm{~V}\right)$ and amplification of the output voltage $\Delta v$. The steel plate is bended in 20 steps to a maximum strain of $S=0.06 \%$ and unloaded in 20 additional steps. On every step, 1000 samples were taken using a data acquisition card (sampling frequency $\mathrm{f}_{\mathrm{s}}=1 \mathrm{kHz}$ ) and averaged. The bending tests are performed in an air-conditioned lab.

The relative change in resistance and the gauge factor $\mathrm{k}$ is calculated using equation (1).

$\frac{\Delta R}{R_{0}}=\mathrm{k} \cdot \mathrm{S} \approx 4 \cdot \frac{\Delta v}{V_{0}}$

Fig. 5 shows the relative change in resistance of both gauges over the applied strain. The reference strain gauge shows a maximum relative change in resistance of $\Delta R / R_{0}=13.46 \cdot 10^{-4}$, which results in a gauge factor of 2.24. The laser-patterned strain gauge reveal $\Delta R / R_{0}=15.71 \cdot 10^{-4}$. This yields to a gauge factor of 2.61 .

\section{Conclusion}

Laser-patterning of metal-based hot stamping foil is a fast, inexpensive and easy method to create individually shaped electrically conductive structures. Furthermore it is possible to design patterns capable of sensing tasks, esp. strain gauges. The gauges can be transferred to surfaces using heat and pressure. No additional glue is needed, since the stamping foils are available with an adhesive layer. First bending tests on strain gauges made of gold reveal a gauge factor of 2.61 , which is to be expected since the change in resistance can be attributed to geometric terms rather than to piezoresistive effects. Our current research is focusing on optimizing the laser process parameters to achieve a higher precision in the designated base resistance. Furthermore, the ideal pressure to bond the strain gauges has to be investigated. 


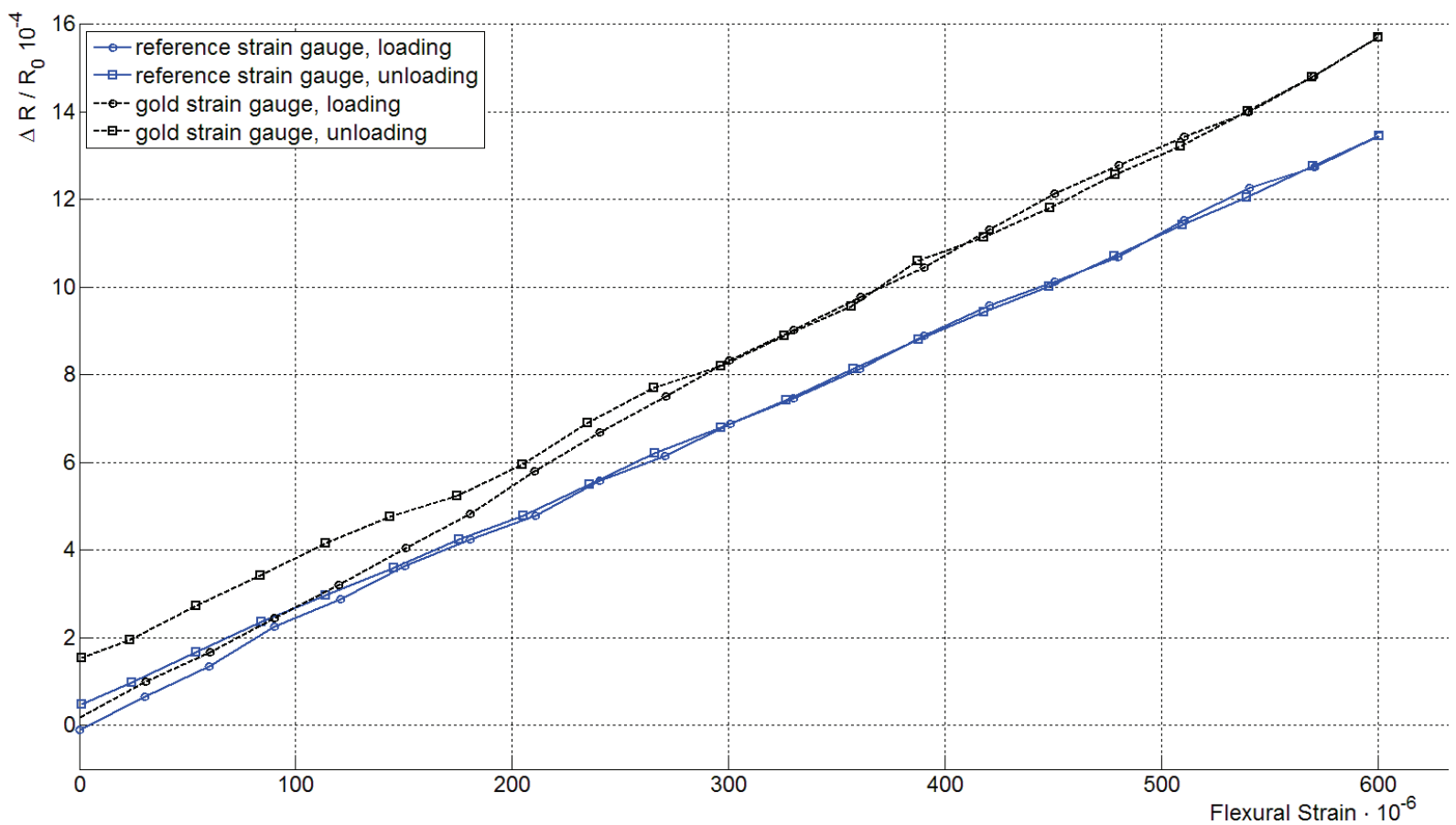

Fig. 5: Results of the bending test: A strain gauge made of laser-patterned hot stamping foil in comparison to a commercial strain gauge.

\section{References}

[1] A. Lyashenko, E. Dörsam: Functional Hot Stamping, Advancing Print \& Coatings Group, Swansea, Wales, UK (2013)

[2] A. Lyashenko, Untersuchung des Prägefoliendrucks im Hinblick auf die Anwendung im Elektronikbereich, PhD Thesis, Darmstadt, Germany (2014)

[3] J. Lei, H. Will, Thin-film thermocouples and strain-gauge technologies for engine applications, Sensors and Actuators 65 (1998)

[4] J. Duesing, O. Suttmann, J. Koch, U. Stute, L. Overmeyer, Ultrafast Laser Patterning of Thin Films on 3-D Shaped Surfaces for Strain Sensor Applications, JLMN-Journal of Laser Micro/Nanoengineering 7 (2011); doi: 10.2961/jlmn.2012.03.0014

[5] J. Rausch, L. Salun, S. Griesheimer, M. Ibis, R. Werthschützky, Printed resistive strain sensors for monitoring of lightweight structures, Proceedings of SPIE (2011) 